\title{
VIEWPOINT
}

\section{Quality in health care: a role for the law?}

\section{J McHale}

Qual Saf Health Care 2002;11:88-91

This paper considers the way in which English law can and does play a part in ensuring quality standards in healthcare practice. It examines the enhanced scope for judicial scrutiny of standards of care and the role played by law in the form of statutory regulation. There is an increasing degree of legal involvement in healthcare decision making. The law may provide some effective checks and balances to quality but, at the same time, the limits of the law as an effective regulator of quality have to be recognised because of the multifaceted nature of clinical judgment.

T he health service in the UK has been influenced over the last few years by the rhetoric of the need for "quality care" as part of the clinical governance structure. ${ }^{1-3}$ At the same time, public confidence in the quality of care delivered by healthcare practitioners has been diminished by a series of events. The report of an extensive public inquiry chaired by Professor Ian Kennedy concerning the conduct of paediatric cardiac services at Bristol Royal Infirmary and, in particular, the activities of the surgeon James Wisheart and his colleagues has recently been published. ${ }^{4}$ The Bristol Inquiry Report concluded that 30-35 children on whom surgery had been performed at Bristol Royal Infirmary between 1991 and 1995 had died unnecessarily because of substandard care with no dedicated children's intensive care unit, no mechanism to monitor quality adequately, and poor organisation. It was exceedingly critical of the paternalistic approach of clinicians and the "club culture". The report came at a time when confidence in the medical profession in the UK had slumped dramatically following a series of other controversial incidents questioning medical professional judgment. Notable amongst these was the scandal of the unauthorised retention of vast stores of human material including children's organs in hospitals around the country as exemplified, in particular, by the public inquiry into the events at the Royal Liverpool Children's Hospital (Alder Hey). ${ }^{5}$

One aspect of these events is the inadequate regulation and scrutiny of clinical practices. A series of extensive wide ranging recommendations were made in the Bristol Inquiry Report with the aim of ensuring that-as far as possible-the events at Bristol are not replicated in the future under the following main headings: respect and honesty; a health service which is well led; competent healthcare professionals; the safety of care; care of an appropriate standard; public involvement through empowerment; and the care of children. The focus of this paper is not, however, an examination of the Bristol Inquiry Report as such, although it does draw upon its recommendations. Instead, what this paper seeks to explore is the part that the law may play in facilitating quality in healthcare practice. It focuses on two main aspects in which the law may be involved: (1) through judicial involvement in scrutinising the standards of care in the courtroom using the operation of judicial scrutiny in medical negligence cases as a specific example, and (2) through explicit statutory regulation and gives examples of statutory forms of quality of healthcare practice in the UK. It suggests that the law may be an effective scrutiniser and regulator, but that it also has its limitations in determining what is "quality care" and "good practice" because of the complex multifaceted nature of much clinical decision making.

"the law may be an effective scrutiniser and regulator, but it has its limitations in determining what is 'quality care' and 'good practice' because of the complex multifaceted nature of much clinical decision making"

\section{QUALITY IN HEALTH CARE AND THE COURTS}

Healthcare practitioners owe a duty of care to their patients and, if they break that duty and harm results, then liability may accrue in the tort of negligence. English law does not only impose obligations in negligence upon the individual clinician but, in addition, the organisation may itself be held to be liable in the tort of negligence through "direct liability" for failure to provide a "safe system". ${ }^{6}$ The legal standard of care in the UK which healthcare practitioners owe to their patients has been rooted in professional practice - the well known Bolam test ${ }^{7}$ - which, as stated by Judge McNair, provides that a doctor:

". . . is not guilty of negligence if he has acted in accordance with a practice accepted as proper by a responsible body of medical men."

This approach was followed over several years in other areas of healthcare litigation such as consent to treatment. ${ }^{8-12}$ While in a few cases judicial adherence to the "party line" wavered slightly and the English courts confirmed their ability to scrutinise the standard of professional practice, ${ }^{13}$ such cases were the aberration, not the rule. Admittedly, the professional practice standard itself is not static so that, for example, over the last decade in the area of consent to treatment there has been a gradual trend towards broader disclosure of information to patients highlighted through professional practice guidelines. However, it is still a professionally based standard.

Nonetheless, the House of Lords in the Bolitho case in 1997 made statements which have been 
interpreted to suggest that today there is greater judicial willingness to scrutinise the opinion expressed by the body of professional practice. ${ }^{14}$ Lord Browne Wilkinson stated that:

"In particular where there are questions of assessment of the relative risks and benefits of adopting a particular medical practice, a reasonable view necessarily presupposes that the relative risks and benefits have been weighed by the experts in forming their opinions. But if, in a rare case, it can be demonstrated that the professional opinion is not capable of withstanding logical analysis, the judge is entitled to hold that the body of opinion is not reasonable or responsible. I emphasise that in my view it will be very seldom right for a judge to reach the conclusion that views genuinely held by a competent medical expert are unreasonable."

In the aftermath to this case some commentators went so far as to suggest that Bolitho was the new Bolam. However, this was not totally true. Their Lordships were, in fact, quite circumspect in their approach. Overturning the responsible body of professional opinion is, in practice, likely to be quite difficult. What the decision in Bolitho did was to send out a signal and one which has been followed in later cases. In the Bolitho case Lord Brown Wilkinson excluded from his discussion the issue of disclosure of risk. However, the courts have latterly applied the Bolitho case to diagnosis and treatment in Pearce $v$ United Bristol NHS Trust. ${ }^{15}$ Lord Woolf held that:

"if there is a significant risk which would affect the judgment of a reasonable patient, then in the normal course it is the responsibility of a doctor to inform the patient of that significant risk if the information is needed so that the patient can determine for him or herself as to what course that she should adopt."

While on the facts of that particular case the plaintiffs failed to establish negligence, nonetheless the approach taken here is indicative of a greater willingness to scrutinise standards of professional opinion. ${ }^{16}{ }^{17}$ Jones has suggested that, in the light of this case, it could be argued that "no reasonable doctor would fail to disclose a risk regarded as significant by a reasonable patient."18

The implications of the judgments in Bolitho and Pearce are yet to be fully explored by the courts. However, it is undoubtedly the case that there is the prospect of enhanced judicial scrutiny over clinical practice in the future in the law of negligence. Clinicians need to be appreciative of the fact that reliance upon professional standards - whether in the form of recognised clinical techniques or in professional codes of ethics-will not necessarily be regarded as determinative in the courtroom.

Clinical practice may also be subject to scrutiny through the operation of the Human Rights Act 1998 which allows the court to have regard to the provisions of the European Convention of Human Rights. While this statute does not elevate the English courts to the power of a Supreme Court, such as that in the USA, nonetheless where legislation is in conflict with the Convention the court does have the power to make what is known as a "declaration of incompatibility" which may lead the Government to introduce remedial legislation. ${ }^{19}$ The Convention does not recognise any one specific "right to health", but there are a number of rights which can be used in healthcare cases such as Article 2 (the right to life), Article 8 (the right to privacy of home and family life), Article 9 (freedom of conscience and religion), and Article 12 (the right to marry and found a family). The Convention rights may be raised in general legal proceedings or through a process of "judicial review" of decisions. Judicial review is the procedure enabling the challenge of the legality of the decisions of "public bodies" or bodies exercising public functions. Challenges may be brought under one of three broad headings: illegality, irrationality, and procedural impropriety. ${ }^{20}$ The powers of the Secretary of State for Health under the National Health Service Act 1977 have been subject to challenge under this heading. Section 3, for instance, provides that the Secretary of State shall provide:

"to such extent as he considers necessary to meet all reasonable requirements: (a) hospital accommodation, ... (c) medical, dental, nursing and ambulance services, (d) such other facilities for the care of expectant and nursing mothers and young children as he considers are appropriate.... [and] (e) such facilities for the prevention of illness, the care of persons suffering from illness and the aftercare of persons suffering from illness as he considers are appropriate...".

In the past such challenges were consistently unsuccessful. ${ }^{21}{ }^{22}$ However, in a number of recent cases the courts have been prepared to review policies which had the effect of excluding groups from clinical procedures-for example, gender reassignment surgery ${ }^{23}$ or a decision to deny access to the drug beta-interferon on the basis that it could only be made available as part of a clinical trial even though all national trials of this drug had ceased at that time. ${ }^{24}$ It has been questioned whether the Human Rights Act 1998 will make a difference and whether litigants may be able to use the Human Rights Act to challenge decisions regarding access to resources and standards of health care through the application of principles such as Article 2 of the European Convention of Human Rights. One major difficulty facing litigants in attempting to bring actions for judicial review is that, even if they succeed technically in establishing their case, this does not mean that a situation may alter. It is simply a review of the decision and does not constitute an appeal mandating the professional body to challenge the situation. They may decide to take a different approach but, alternatively, they may reconsider the issue and reach an identical conclusion.

The courts can play an effective role in promoting quality in healthcare practice up to a point. Judicial determinations establishing legal principles may feed into future improvements in the quality of care. Moreover, the very fact that the courts are no longer prepared to "rubber stamp" the views of clinical practitioners sends out a very important message - the inevitable "deterrent factor". But, as indicated above, this is usually a reactive role-closing the door after the horse has bolted. While clinicians may seek guidance on a particular issue-for example, whether to sterilise a mentally handicapped woman or switch off a life support system, such guidance is sought comparatively rarely. Moreover, recourse to the courts is an exceedingly protracted and expensive way to address these questions. In the area of medical negligence, for example, cases are increasing in volume and indeed there have been suggestions that such actions should be diverted from the courtroom to some form of no-fault compensation scheme akin to the approach taken in Sweden and New Zealand. Kennedy in the Bristol Inquiry Report indicated the need for review of the compensation system. Concerns over the present system of clinical negligence have led the Government to issue a consultation paper "Clinical negligence: what are the issues and options for reform?"25 The prospect of litigation also may not facilitate the best healthcare practice ultimately as it may simply have the effect of encouraging defensive medicine or drive practitioners from certain areas of clinical practice known to carry particular risks-for example, obstetrics and gynaecology.

Litigation is not the only method through which standards in healthcare practice may be facilitated and promoted; an arguably more effective mechanism is through the use of law to establish regulatory mechanisms.

\section{FACILITATING QUALITY THROUGH REGULATION: THE ROLE OF LEGISLATION?}

Alongside the part played by the courts in determining the appropriate standard of care, legislation may also facilitate this process in a proactive manner. While there already exists certain statutory regulations of healthcare professionals through, for example, the Medical Act 1983 and the Nursing, Midwives and Health Visitors Act 1997, such legislation operates in a very general way and the professional bodies have traditionally been left largely to regulate themselves and to determine their own standards of practice. This is set to 
change with the establishment of the Council of Healthcare Regulators, a body proposed under the NHS Plan. This body will draw upon representation from each of the main healthcare professional groups. The Bristol Inquiry Report suggests that this body (which it proposes should be renamed the Council for the Regulation of Healthcare Professionals) should oversee all elements of professional regulation including issues such as education, training, and professional development. ${ }^{4}$

Other than the regulation of the professional bodies, there are several ways in which existing legislative regulation may promote quality in health care. Firstly, Section 18 of the Health Act 1999 places a statutory duty of quality upon health authorities, primary care trusts, and NHS trusts. They must put in place arrangements for the purpose of monitoring and improving the quality of health care provided to individuals. It is enforceable through the power of the Secretary of State to issue directions to these bodies and also through the Commission for Health Improvement (CHI), a new body established under the 1999 Act. The two bodies particularly linked with clinical governance concerned with quality in health care are the CHI and the National Institute for Clinical Excellence (NICE), the latter a special health authority established under statutory instrument. ${ }^{26}$ NICE provides guidance as to "best practice" for patients, health professionals, and the public. Such guidance covers the clinical management of specific conditions and also individual health technologies such as medicines, diagnostic devices, and procedures. It is involved in the development of clinical audits with the aim of enabling health professionals to monitor their practice and in the assessment of how a particular technology has been used nationally through the merger of clinical audit findings. The CHI was established under Section 19 of the Health Act 1999 (see also Schedule 2) and is concerned with the implementation of clinical governance, National Service Frameworks, and the guidelines issued by NICE. It will visit each NHS trust, primary care trust, and health authority every four years. It also has the role of assisting the NHS in the identification of serious or persistent clinical problems and is responsible for overseeing and assisting external NHS incident inquiries.

There are also a number of bodies operating under statute in specific areas which are concerned with safeguarding quality in healthcare provision. In the area of mental health the Mental Health Act Commission, established under the Mental Health Act 1983, has the role of drawing up the Mental Health Act Code of Practice and monitoring the operation of the Act including making hospital visits. The performance of infertility clinics is regulated through the Human Fertilisation and Embryology Authority established under the Human Fertilisation and Embryology Act 1990. This body is concerned with the licensing of clinics for both the provision of infertility services and embryo research. It also issues guidance in the form of a Code of Practice. The conduct of transplant operations between unrelated donors is the subject of scrutiny by the Unrelated Live Transplant Regulatory Authority established under the Human Organ Transplants Act 1989. Such bodies may have two roles. They may be seen primarily as firewatchers policing the operation of a particular area, and may also have a role as a firefighter when things do go wrong.

In addition, there are certain regulatory agencies established through legislation which, while they are not exclusively concerned with health care, nonetheless facilitate standards of good practice-for example, the Data Protection Act 1998 places safeguards around the use of health data and makes such use subject to the data protection principles. This legislation was enacted following the European Data Protection Directive, a document which in turn was driven by concerns regarding safeguarding individual privacy. The operation of the Act is overseen by the Information Commissioner. The Health and Safety at Work Act 1974 is perhaps the oldest of such regulatory mechanisms.
Finally, there are those pieces of general legislation which facilitate quality care more indirectly and which are not necessarily accompanied by a statutory agency. In the 1990s there was a heated debate regarding whistleblowing in the NHS following the case of Grahame Pink, a nurse who blew the whistle on what he regarded as poor standards of care of elderly patients in a Stockport hospital. ${ }^{27}$ Today the Public Interest Disclosure Act 1998 provides certain legislative safeguards for those who blow the whistle upon poor standards of care. Such legislation may guide good practice in a general sense, but the legislation itself can only go so far. While it may lead to longer term improvements in the organisation, the position of the whistleblower is ultimately vulnerable since, if he or she has been victimised or dismissed, the practical prospects for reinstatement are very low. It is interesting to note that Dr Stephen Boisin who "blew the whistle" on the events at Bristol Royal Infirmary apparently had difficulties in obtaining further employment in the UK and is now working in Australia.

At first sight, then, the law can be influential through the creation of such regulatory bodies. However, one problem is whether we are creating too many agencies and organisations across health care with too many guidelines which may make it difficult for practitioners-already bombarded by guidance from their professional agencies-to determine which guidance to follow and what really is good clinical practice. This, of course, is something which can arise whether such organisations are created under statutory authority or not (indeed, at present the greatest number of guidelines probably arise from the vast proliferation of non-statutory bodies ranging from the Medical Research Council to the Royal Colleges). Nonetheless, the number of statutory agencies is increasing and coordination between these agencies and the range of existing guidelines is undoubtedly an issue which needs to be addressed. The Bristol Inquiry Report recognised this and suggested the establishment of overarching bodies, notably a council for the quality of health care. This body would be independent of government and oversee, for example, NICE, $\mathrm{CHI}$, and another recently created body, the National Patient Safety Agency. The Report commented that there was a need for a body to be entrusted with the task of setting standards for clinical care and that NICE may take over this task. ${ }^{4}$ It also proposed the establishment of a single body to validate healthcare organisations, ensuring that the standards which are produced by bodies such as the Royal Colleges and the Health and Safety Executive are coherent and consistent. These are sensible recommendations and it is to be hoped that they are soon adopted.

\section{FACILITATING QUALITY IN CARE: THE LIMITS OF THE LAW}

Law can provide checks and balances upon healthcare practice. On some issues it can be effective as a delineator or calibrator of standards. The benchmark can be fixed as a legal principle-for example, in relation to the level of provision of information to patients or to research subjects. On other issues, however, while the law can provide the framework, it may be of limited assistance in providing guidance as to what approach should be taken in a specific case, particularly where the clinical determination involves difficult moral issues. Take, for example, the decision whether to break a patient's confidentiality to disclose genetic information to a relative. The principle of confidentiality is one recognised as not being absolute in law or in clinical practice. The healthcare professional in that situation may face a very difficult choice, bearing in mind that he or she is working within very uncertain ethical/legal boundaries. Secondly, with regard to consent to treatment, the courts will review the quantity of information given and the professional practice test (the importance of clarifying and regulating the consent process is 
highlighted in the Bristol Inquiry Report itself), but major complex questions may arise concerning the determination of capacity to consent to treatment. ${ }^{28}$ The law may confirm the right of the competent patient to refuse treatment and provide guidance in determining competence but, in practice, much discretion is afforded to healthcare professionals themselves in making that particular judgment. As noted above, while guidance as to which approach to be taken may be sought from the courts, in practice this can only be done in rare cases. A further illustration of the limitations of law is shown in relation to infertility treatment. The Human Fertilisation and Embryology Authority has the task of dealing with issues concerning the provision of modern reproductive technologies and embryo research which, while they involve questions of law, are at the same time intertwined with considerations of ethics and social policy. The need for constant reassessment of many of these types of decisions in the light of technological developments and developing ethical approaches to such new technologies indicates only too clearly the limits of the law as a responsive regulator. It also perhaps leads us to question how appropriate the use of the term "quality" is in describing the actions of healthcare professionals. However, this is a question which is far too broad to address within the scope of this paper.

"while the law may provide a framework and facilitate quality in health care, guide practice and set boundaries, the expectations ... must not be unrealistic"

\section{CONCLUSIONS}

English law is playing an enhanced role in facilitating quality in health care, in the courtroom through scrutinising incidents of alleged clinical negligence and through the operation of statutory agencies in monitoring practice. It is likely that judicial scrutiny of the professional practice standard will continue, particularly in the light of the Human Rights Act 1998. This scrutiny may give rise to statements of principles which can be carried forward into practice itself. Healthcare practice and quality of health care are likely also to be affected by other legal demands, most notably that of the European Union. While the European Union does not at present have general competence to regulate on health law and health policy, it is involved in regulation in specific areas such as pharmaceuticals and medical devices and is likely to play an enhanced regulatory role in the future. ${ }^{29}$ There is also the prospect, since Bristol, for further development of existing statutory regulatory agencies such as NICE and of the establishment of new organisations. But, while the law may provide a framework and facilitate quality in health care, guide practice and set boundaries, the expectations made of the law must not be unrealistic. Self-evidently, it is impossible to legislate comprehensively for all healthcare decisions; there are still matters which are not amenable to straightforward guidance nor to straightforward solutions because they give rise to acute moral and ethical dilemmas. As, for example, with the development of clinical guidelines and protocols, the law can establish principles and standards, and structured approaches can be facilitated, but ultimately there will be grey areas, there will be hard cases. In such situations the clinician may be advised to seek guidance from the court as to whether his/her

\section{Key messages}

- The law can provide a framework and facilitate quality in health care.

- The law may be involved in healthcare quality through judicial scrutiny of standards of care in the courtroom (such as medical negligence) and through statutory regulation.

- Although the law may be an effective scrutiniser and regulator, it has limitations in determining what is "quality care" and "good practice" because of the complex multifaceted nature of much clinical decision making.

action is legitimate but there may be no "correct" answer. Nonetheless there is a risk that clinicians always view lawyers as a threat to practice. In fact, law may facilitate best practice and assist in guiding clinical approaches. Frank Dobson was surely overstating the point when he said that the only place for a lawyer in the NHS was on the operating table!

\section{ACKNOWLEDGEMENT}

The author gratefully acknowledges the incisive comments of the reviewer of this piece. All errors and omissions which remain are, of course, her own.

\section{REFERENCES}

1 Department of Health. The new NHS: modern dependable. CM 3807 London: Department of Health, 1997

2 Department of Health. A first class service: quality in the new NHS. 1998/113 HSC. London: Department of Health, 1998.

3 Quality care and clinical excellence. 1998.

4 Bristol Inquiry Report. http://www.bristol-inquiry.org.uk, 2001

5 Report of the Inquiry into the Royal Liverpool Children's Hospital (Alder Hey). http://www.rclinquiry.org.uk, 2001

6 Robertson v Nottingham HA. [1997] 8 Med LR 1 CA.

7 Bolam v Friern Hospital Management Committee. [1957] 1 WLR 587

8 Maynard v West Midlands HA. [1984] 1 WLR 643.

9 De Freitas v O'Brien. [1995] 6 Med LR 108.

10 Sidaway v Board of Governors of the Bethem Royal Hospital. [1985] AC 871.

11 Robertson G. Informed consent to medical treatment. Law Quart Rev 1981;97:102.

12 Kennedy I. The patient on the Clapham omnibus. In: Treat me right: law and medical ethics. Oxford: Oxford University Press, 1991.

13 Smith v Tunbridge Wells Health Authority. [1994] 5 Med LR 334.

14 Bolitho v City and Hackney Health Authority. [1997] 1 WLR 1151.

15 Pearce v United Bristol NHS Trust. [1999] PIQR P53 (CA).

16 Grubb A. Commentary. [1999] 7 Med LR 61

17 Brazier M, Miola J. Bye-bye Bolam: a medical litigation revolution? [2000] 8 Med LR 85-114.

18 Jones M. Informed consent and other fairy stories. [1999] 7 Med LR 103.

19 Human Rights Act. Section 4. 1998

20 Council of Civil Service Unions v Minister for the Civil Service (GCHQ case).

21 R v Secretary of State for Social Services, ex p Hincks. [1980] 1 BMLR 93.

22 R v Cambridge DHA, ex p B. [1995] 1 WLR 898.

23 North West Lancashire Health Authority v A, D and G. [1999] Lloyd's Rep Medical 399.

24 R v North Derbyshire Health Authority, ex p Fisher. [1997] 8 Med LR 327.

25 Department of Health. Clinical negligence: what are the issues and options for reform? http://www.doh.gov.uk/clinicalnegligencerefon, 2001.

26 National Institute for Clinical Excellence (Establishment and Constitution) Order 1999. SI 1999/260.

27 McHale JV. Whistle blowing in the NHS. J Soc Welfare Family Law 1992;5:363-72.

28 Re MB. [1987] 38 BMLR 175 CA.

29 Hervey T. European social law and policy. London: Longman, 1998: $135-57$ 